\title{
Right coronary artery patency as a modulator for unprotected left main PCI risk: myth or reality?
}

\author{
Francesco Burzotta ${ }^{1,2}$, Mila Kovacevic ${ }^{3,4}$, Carlo Trani1, ${ }^{1,2}$ \\ 'Fondazione Policlinico Universitario Agostino Gemelli IRCCS, Rome, Italy \\ 2Università Cattolica del Sacro Cuore, Rome, Italy \\ ${ }^{3}$ Faculty of Medicine, University of Novi Sad, Novi Sad, Serbia \\ ${ }^{4}$ Institute of Cardiovascular Diseases of Vojvodina, Cardiology Clinic, Sremska Kamenica, Serbia
}

\section{Related article}

by Skorupski et al., see p. 631

\section{Correspondence to: Francesco Burzotta $\mathrm{MD}, \mathrm{PhD}$, \\ Fondazione Policlinico Universitario Agostino Gemelli IRCCS, Università Cattolica del Sacro Cuore, L.go A. Gemelli 1, 00168 Rome, Italy, phone: +3906 30154187, e-mail: \\ francesco.burzotta@unicatt.it Copyright by the Author(s), 2021 \\ Kardiol Pol. 2021; 79 (6): 609-611; DOI: 10.33963/KP.a2021.0031 Received: June 1, 2021 Revision accepted: June 1, 2021 Published online: June 2, 2021}

According to the evolving definition for highrisk percutaneous coronary intervention $(\mathrm{PCl})$ [1], unprotected left-main (ULM) disease is recognized as one of the unfavorable features helping to identify high-risk PCl patients. Randomized trials made it possible to highlight the overall coronary artery tree involvement as a potent modulator of $\mathrm{PCl}$ efficacy [2] so that only patients with ULM disease and low $(\leq 22)$ Synergy Between PCI With Taxus and Cardiac Surgery (SYNTAX) score have a class I recommendation for $\mathrm{PCl}$. Nevertheless, remarkable progress in $\mathrm{PCl}$ techniques and devices facilitated offering $\mathrm{PCl}$ to many ULM patients with a wide spectrum of anatomic complexity [3].

The experience of interventionalists early started to consider the possible "protective" value of right coronary artery (RCA) flow during ULM PCI. Indeed, considering the large region of jeopardized myocardium in the absence of a patent RCA concern about the possible occurrence of hemodynamic deterioration during ULM PCl is justified.

The SYNTAX score provided numbers (proven to be useful for ULM patients) that are influenced by RCA dominance, RCA patency, and RCA disease pattern. For instance, RCA patency disease by itself does not imply a strong SYNTAX score rise. On the opposite, a long, calcified, chronic total occlusion (CTO) dominant RCA lesion has a major impact on the SYNTAX score.

When assessing the impact of RCA features on ULM PCl, the major focus of the past investigations was on RCA CTO. Of note, com- plex anatomy and CTO are the most frequent reasons for referring patients to CABG [4]. According to the early publication of Capodanno et al. [5], patients with concomitant LM and RCA disease had higher cardiac mortality after LM PCI (17.7\% vs $6.7 \% ; P=0.056)$ than those without RCA disease. Importantly, mortality in patients with RCA CTO was extremely higher (30\% vs $6.7 \% ; P=0.015$ ) in comparison to the patients without RCA CTO. Similarly, Migliorini et al. [6] noticed significantly higher 6-month (12.8\% vs 3.6\%; $P<0.02)$ and 3-year mortality rates $(23.6 \%$ vs $10.3 \% ; P<0.03)$ in patients with RCA CTO than in those without RCA CTO. Moreover, RCA CTO was recognized as an independent predictor of 3-year cardiac mortality (HR, 2.15 [1.02-4.05]; $P=0.043)$. In line with these results, Takagi et al. [7] reported that in patients undergoing ULM PCl, cardiac death rate was higher in the presence of residual RCA CTO (HR, 2.163 [1.018-4.597]; $P=0.045)$ at 1466 days of follow-up. Additionally, they showed that recanalization of RCA CTO significantly improves long-term survival $(P=0.010)$.

In such a context, Skorupski et al. [8] assessed the impact of the absent functional RCA support on prognosis of patients undergoing ULM PCI. They applied an original definition of no "RCA support" which included a broader spectrum of patients, not only with RCA CTO but also with significant stenosis or minor RCA. They concluded that long-term all-cause mortality at a median follow-up of 1149 days did not differ among the groups ( $23 \%$ vs $20 \%$; 
$P=0.37$ in patients without and with RCA support, respectively). Moreover, RCA CTO (found in $14.3 \%$ of patients) did not increase all-cause mortality.

How to explain these conflicting results of Skorupski et al. [8] in comparison to the previous retrospective trials/ /registries?

A logical explanation might come from differences in the characteristics of the study population investigated in different studies. Indeed, the relevance of RCA support during ULM PCI is strongly modulated by:

- left ventricular ejection fraction;

- technical complexity of PCl on the left system;

- clinical conditions.

In these regards, the study population enrolled by Skorupski et al. [8] was characterized by a favorable combination of high ejection fraction (mean value around 55\%), low SYNTAX score (mean value 21), and low incidence of 3-vessel disease (7.5\%). Furthermore, most of the patients were stable and EuroSCORE II (a strong predictor of adverse clinical outcome after $\mathrm{PCl}$ as previously reported) [9] was as low as $1.45 \%$. In other words, RCA support failed to impact the outcome of $\mathrm{PCl}$ in a "selected" subgroup of ULM patients exhibiting low risk of both acute hemodynamic compromise and late adverse outcome, as compared with other studies. Consequently, the reported findings cannot translate to other patient subsets.

Another important issue is related to the size of RCA (ranging between super-dominant and recessive) and the type of eventually present coronary lesions (ranging between plaques with borderline hemodynamic significance to sub-occlusions and collateralized chronic total occlusions). Skorupski et al. [8] tried to address this issue but the three categories they applied to RCA lesions (recessive, significant stenosis and (TO) cannot entirely describe the relevance of hemodynamic support provided during ULM $\mathrm{PCl}$. According to a recent study [10], in patients with ULM $\mathrm{PCl}$, the performance of $\mathrm{PCl}$ on significant (>70\%) RCA stenosis during the same hospitalization might reduce 30-day cardiovascular death. All together, these observations call for patient-to-patient decisions which should take into account the feasibility of achieving reasonable levels of revascularization completeness (not to leave unrevascularized stenoses supplying large areas of ischemic myocardium [11]).

As a final remark, it is crucial to highlight the possibility to deal with patients exhibiting extreme challenges like complex, calcific ULM bifurcation disease and very low ejection fraction. In these circumstances:

- a patent RCA can provide minor support so that mechanical circulatory support can be considered to increase procedure safety (moving from high risk to "protected" $\mathrm{PCl}[12])$;
- untreated proximal lesion in a large RCA may imply large residual jeopardized myocardium resulting in impaired late outcome despite successful protected PCI [13].

\section{Article information}

Conflict of interest: None declared.

Open access: This article is available in open access under Creative Common Attribution-Non-Commercial-No Derivatives 4.0 International (CC BY-NC-ND 4.0) license, allowing to download articles and share them with others as long as they credit the authors and the publisher, but without permission to change them in any way or use them commercially. For commercial use, please contact the journal office at kardiologiapolska@ptkardio.pl.

How to cite: Burzotta F, Kovacevic M, Trani C. Right coronary artery patency as a modulator for unprotected left main $\mathrm{PCl}$ risk: myth or reality? Kardiol Pol. 2021; 79(6):609-611, doi: 10.33963/KP.a2021.0031.

\section{REFERENCES}

1. Rihal CS, Naidu SS, Givertz MM, et al. Society for Cardiovascular Angiography and Interventions (SCAI), Heart Failure Society of America (HFSA), Society of Thoracic Surgeons (STS), American Heart Association (AHA), and American College of Cardiology (ACC). 2015 SCAI/ACC/HFSA/STS clinical expert consensus statement on the use of percutaneous mechanical circulatory support devices in cardiovascular care: endorsed by the American Heart Association, the Cardiological Society of India, and Sociedad Latino Americana de Cardiología Intervencionista; affirmation of value by the Canadian Association of Interventional Cardiology-Association Canadienne de Cardiologie d'Intervention. J Am Coll Cardiol. 2015; 65(19): 2140-2141, doi: 10.1016/j.jacc.2015.02.043, indexed in Pubmed: 25861962.

2. Neumann FJ, Sousa-Uva M, Ahlsson A, et al. ESC Scientific Document Group. 2018 ESC/EACTS Guidelines on myocardial revascularization. Eur Heart J. 2019; 40(2): 87-165, doi: 10.1093/eurheartj/ehy394, indexed in Pubmed: 30165437.

3. Burzotta F, Lassen JF, Banning AP, et al. Percutaneous coronary intervention in left main coronary artery disease: the 13th consensus document from the European Bifurcation Club. Eurolntervention. 2018; 14(1): 112-120, doi: 10.4244/EIJ-D-18-00357, indexed in Pubmed: 29786539.

4. Christofferson RD, Lehmann KG, Martin GV, et al. Effect of chronic total coronary occlusion on treatment strategy. Am J Cardiol. 2005; 95(9): 10881091, doi: 10.1016/j.amjcard.2004.12.065, indexed in Pubmed: 15842978.

5. Capodanno D, Di Salvo ME, Tamburino C. Impact of right coronary artery disease on mortality in patients undergoing percutaneous coronary intervention of unprotected left main coronary artery disease. Eurolntervention. 2010; 6(4): 454-460, doi: 10.4244/EIJ30V6I4A77, indexed in Pubmed: 20884432.

6. Migliorini A, Valenti R, Parodi G, et al. The impact of right coronary artery chronic total occlusion on clinical outcome of patients undergoing percutaneous coronary intervention for unprotected left main disease. J Am Coll Cardiol. 2011; 58(2): 125-130, doi: 10.1016/j.jacc.2011.02.050, indexed in Pubmed: 21718907.

7. Takagi K, lelasi A, Chieffo A, et al. Impact of residual chronic total occlusion of right coronary artery on the long-term outcome in patients treated for unprotected left main disease: the Milan and New-Tokyo registry. Circ Cardiovasc Interv. 2013; 6(2): 154-160, doi: 10.1161/CIRCINTERVENTIONS.112.000079, indexed in Pubmed: 23572491.

8. Skorupski WJ, Grygier M, Araszkiewicz A, et al. The impact of right coronary artery support on the outcomes of patients with unprotected left main disease undergoing percutaneous coronary intervention. Kardiol Pol. 2021, 79(6): 631-637, doi: 10.33963/KP.15972, indexed in Pubmed: 33909388.

9. Saffioti S, Coluccia V, Burzotta F, et al. Value of EuroSCORE II in predicting total and cardiac mortality in patients undergoing percutaneous coronary interventions. Am J Cardiol. 2014; 113(4): 745-746, doi: 10.1016/j. amjcard.2013.11.020, indexed in Pubmed: 24484866. 
10. Lee $\mathrm{CH}$, Chong SZ, Hsueh SK, et al. Residual right coronary artery stenosis after left main coronary artery intervention increased the 30-day cardiovascular death and 3-year right coronary artery revascularization rate. J Interv Cardiol. 2020; 2020:4587414, doi: 10.1155/2020/4587414, indexed in Pubmed: 32607081.

11. Gaba P, Gersh BJ, Ali ZA, et al. Complete versus incomplete coronary revascularization: definitions, assessment and outcomes. Nat Rev Cardiol. 2021; 18(3): 155-168, doi: 10.1038/s41569-020-00457-5, indexed in Pubmed: 33067581.
12. Burzotta F, Crea F. "Protected" PCl: time to act. Minerva Cardioangiol. 2018; 66(5): 547-550, doi: 10.23736/S0026-4725.18.04704-7, indexed in Pubmed: 29687701.

13. Aurigemma C, Burzotta F, Chieffo A, et al. IMP-IT Investigators. Clinical impact of revascularization extent in patients undergoing impella-protected $\mathrm{PCI}$ enrolled in a nationwide registry. JACC CardiovasC Interv. 2021; 14(6): 717-719, doi: 10.1016/j.jcin.2021.01.017, indexed in Pubmed: 33736787. 